\title{
Editorial
}

\section{REFLEXIONES SOBRE EL “CASO PETRO”}

\section{Juan Carlos Villalba Cuéllar, Editor Andrés González Serrano, Coeditor}

Lo que han llamado -o se puede llamar-el "Caso Petro" es, en evidencia, el resultado práctico de la falta de adecuación del sistema normativo colombiano al sistema normativo interamericano. La Constitución Política de 1991, así como nuestro ordenamiento jurídico, en algunos de sus apartados no se ajusta a la Convención Americana sobre Derechos Humanos, este es todo el problema y no otro.

Ahora bien, en un Estado democrático, participativo y pluralista se deben respetar las diferentes interpretaciones y enfoques del "Caso Petro", no podemos olvidar que estamos, al menos formalmente, en un Estado social de derecho. Y es lógico que la visión político-social de este asunto es la que más atrae a la opinión pública y es la que presentan los medios de comunicación. Sin embargo, esta perspectiva del "Caso Petro", es justo la que se evitará, para abordarlo desde la mirada jurídica, habida cuenta que los estudiosos del derecho, deben ser objetivos, independientes e imparciales a la hora de valorar la violación o no de un derecho humano.

Se debe expresar que el "Caso Petro" también podría titularse, entre otros, "Alonso Salazar" o "Samuel Moreno Rojas" o "Jorge Iván Ospina" o "Cielo González", porque no se puede olvidar que la Procuraduría General de la Nación ha impuesto la sanción de destitución, suspensión $e$ inhabilidad a diversos funcionarios elegidos por voto popular, como gobernadores, alcaldes y congresistas (Jiménez, 2013). Se observa además que su facultad disciplinaria la ha ejercido no solo en contra de un único partido político o modelo de pensamiento, lo cual también resultaría irrelevante para el análisis jurídico que proponemos, así como las calidades políticas, sociales e ideológicas de Gustavo Francisco Petro Urrego. La cuestión a analizar es si la facultad del procura- dor general de la nación de destituir e inhabilitar a un funcionario público elegido popularmente a través del voto, es o no contraria a la Convención Americana sobre Derechos Humanos.

Para la Procuraduría General de la Nación es una función constitucional y convencional, que ha ejecutado en numerosas ocasiones, y además ha defendido y argumentado en el procedimiento administrativo adelantado ante su despacho, así como en las diferentes acciones de tutela y acciones de nulidad y restablecimiento del derecho, en las cuales -en resumen- ha señalado:

Por último, frente al argumento de la presunta falta de competencia de la Procuraduría para restringir o suspender legítimamente los derechos políticos de funcionarios de elección popular, por ser esta una supuesta facultad exclusiva de los jueces penales según la interpretación del artículo 23 de la $\mathrm{CADH}$ planteada en la demanda, afirma el escrito del ente de control que no es de recibo, no solo por ser un razonamiento que ya fue desestimado dentro del procedimiento administrativo al ser resuelta la solicitud de nulidad que con base en él presentó el apoderado del Alcalde Mayor de Bogotá, sino por carecer de una base sólida.

Explica así que en la sentencia C-028 de 2006 la Corte Constitucional examinó la ley 734 de 2002 desde la óptica específica del artículo 23 de la CADH y no encontró vicio de convencionalidad alguno.

Considera igualmente que el artículo 30 [de la] $\mathrm{CADH}$ permite que las leyes nacionales fijen límites a los derechos consagrados en la Convención siempre que lo hagan para atender 
fines de interés general, tal como ocurre con el proceso disciplinario en Colombia.

[...] Igualmente defiende la competencia general que la Constitución otorga a la Procuraduría para ejercer el control disciplinario incluso sobre los funcionarios de elección popular, tal como lo reconoció la Corte Constitucional en la reciente decisión contenida en la sentencia SU-712 de 2013 [...] (Consejo de Estado, 2014a, pág. 23).

Sin embargo, es importante indicar que la Convención Americana sobre Derechos Humanos establece en su artículo 23, que:

1. Todos los ciudadanos deben gozar de los siguientes derechos y oportunidades:

a) de participar en la dirección de los asuntos públicos, directamente o por medio de representantes libremente elegidos;

b) de votar y ser elegidos en elecciones periódicas auténticas, realizadas por sufragio universal e igual y por voto secreto que garantice la libre expresión de la voluntad de los electores, y

c) de tener acceso, en condiciones generales de igualdad, a las funciones públicas de su país.

2. La ley puede reglamentar el ejercicio de los derechos y oportunidades a que se refiere el inciso anterior, exclusivamente por razones de edad, nacionalidad, residencia, idioma, instrucción, capacidad civil o mental, o condena, por juez competente, en proceso penal.

Como puede leerse del instrumento interamericano, la restricción es exclusiva, entre otras, por condena, y aclara el mismo, por juez competente en proceso penal. Postura que aceptó (Comisión Interamericana de Derechos Humanos, 2009) y acogió la Comisión Interamericana de Derechos Humanos al "estimar que la posible aplicación de una sanción de naturaleza disciplinaria, adop- tada por una autoridad administrativa, podría afectar el ejercicio de los derechos políticos del señor Gustavo Francisco Petro Urrego, quien habría sido elegido por votación popular" (CIDH, 2014a, par. 15).

Lo establecido en la Convención Americana y la postura de la Comisión en el proceso cautelar de Gustavo Petro se ponen de presente porque la Procuraduría no ha sido el único ente estatal que defiende la convencionalidad de su facultad sancionadora, pues la Corte Constitucional también lo ha hecho en decisiones de 2006 y 2013, así:

Desde otra perspectiva, la Corte considera que la competencia atribuida constitucionalmente al procurador general de la nación para investigar y sancionar disciplinariamente a quienes desempeñen funciones públicas, inclusive tratándose de cargos de elección popular, es compatible con la Convención Americana sobre Derechos Humanos.

[...] El precepto reconoce algunos derechos políticos, entre ellos el derecho al sufragio pasivo, es decir, a ser elegido. El numeral $2^{\circ}$ establece que la ley podrá reglamentar su ejercicio, entre otras razones, cuando exista condena por un juez competente en el marco de un proceso penal.

Sin embargo, de dicha disposición no se infiere una prohibición a los Estados para que en sus ordenamientos internos consagren otro tipo de restricciones a los derechos políticos, menos aun cuando emanan directamente de sus propias constituciones. En otras palabras, lo que hace el artículo 23 de la Convención es fijar una serie de pautas bajo las cuales el legislador puede regular los derechos allí señalados, pero no establece una relación cerrada (numerus clausus) en cuanto a las eventuales restricciones que constitucionalmente pueden ser impuestas a su ejercicio.

[...] Luego de una interpretación sistemática con los preceptos de la Carta Política, esta 
Corporación concluyó que las sanciones disciplinarias que implican la suspensión del derecho de acceso a cargos públicos $-v$. gr. de congresista- no se oponen a la Constitución ni a la Convención Americana de Derechos Humanos; en consecuencia, declaró la exequibilidad de las normas acusadas: en el caso concreto, el artículo 23 de la Convención Americana sobre Derechos Humanos, tal y como se ha explicado, no se opone realmente a que los legisladores internos establezcan sanciones disciplinarias que impliquen la suspensión temporal o definitiva del derecho de acceso a cargos públicos, con miras a combatir el fenómeno de la corrupción. En igual sentido, la Constitución de 1991, tal y como lo ha considerado la Corte en diversos pronunciamientos, tampoco se opone a la existencia de dichas sanciones disciplinarias, incluso de carácter permanente, pero bajo el entendido de que dicha sanción de inhabilidad se aplique exclusivamente cuando la falta consista en la comisión de un delito contra el patrimonio del Estado.

En suma, contrario a lo sostenido por los demandantes, la facultad que le otorgó el legislador a la Procuraduría General de la Nación para imponer sanciones disciplinarias temporales o permanentes que impliquen restricción del derecho de acceso a cargos públicos, no se opone al artículo 93 constitucional ni tampoco al artículo 23 del Pacto de San José de Costa Rica (2013, pág. 70 a 73).

No obstante lo anterior, la Corte Interamericana de Derechos Humanos en el "Caso López Mendoza" ya abordó el problema jurídico de "si las sanciones de inhabilidad impuestas por decisión de un órgano administrativo son o no compatibles con la Convención Americana", en el cual manifestó:

Así pues, refiriéndose específicamente al caso concreto que tiene ante sí, la Corte entiende que este punto debe resolverse mediante la aplicación directa de lo dispuesto por el artículo 23 de la Convención Americana, porque se trata de sanciones que impusieron una clara restricción a uno de los derechos políticos reconocidos por el párrafo 1 de dicho artículo, sin ajustarse a los requisitos aplicables de conformidad con el párrafo 2 del mismo.

[...] El artículo 23.2 de la Convención determina cuáles son las causales que permiten restringir los derechos reconocidos en el artículo 23.1, así como, en su caso, los requisitos que deben cumplirse para que proceda tal restricción. En el presente caso, que se refiere a una restricción impuesta por vía de sanción, debería tratarse de una "condena, por juez competente, en proceso penal". Ninguno de esos requisitos se ha cumplido, pues el órgano que impuso dichas sanciones no era un "juez competente", no hubo "condena" y las sanciones no se aplicaron como resultado de un "proceso penal", en el que tendrían que haberse respetado las garantías judiciales consagradas en el artículo 8 de la Convención Americana.

[...] En virtud de lo que antecede, la Corte determina que el Estado violó los artículos 23.1.b y 23.2 en relación con el artículo 1.1 de la Convención Americana, en perjuicio del señor Leopoldo López Mendoza (2011, pars. 105, 107 y 109).

En otras palabras, para los dos órganos de protección de derechos humanos del sistema interamericano, la facultad administrativa, y no judicial, por medio de la cual se inhabilita a un funcionario elegido popularmente, no es convencional. Es decir, no se ajusta a lo consagrado en el artículo 23 del instrumento interamericano y, además, podría generar responsabilidad internacional del Estado colombiano por incumplir sus obligaciones internacionales.

No se debe olvidar que los derechos humanos reconocidos en las normas internacionales se deben respetar y garantizar a los seres humanos que estén sujetos a la jurisdicción del Estado; y 
que está prohibido, en principio, tanto por la Convención de Viena como por la Convención Americana el no cumplimiento de una obligación internacional justificándola en la aplicabilidad de una ley interna.

En síntesis, hoy no solo se debe hablar de un control de constitucionalidad sino también de un control de convencionalidad, el cual lo deben ejercer de manera oficiosa los jueces y órganos vinculados a la administración de justicia en todos los niveles. Control que no solo se limita a comparar la norma interna con el tratado internacional -Convención Americana sobre Derechos Humanos-, sino además con la interpretación que del mismo ha hecho la Corte Interamericana de Derechos Humanos.

Es necesario -para los defensores de derechos humanos- promover el desuso de la doctrina que esgrime que el derecho es una herramienta de la política. El "Caso Petro", como otros, debe servir de ejemplo del mal empleo que desde la política se hace del ordenamiento jurídico interno en algunos casos. Al derecho le hace daño su relación con la política y los medios, cuando se utiliza mal. Ahora bien, es deseable que la reforma mediáticamente propuesta por diferentes autoridades estatales de revisar la facultad de la Procuraduría General de la Nación y ajustarla a los tratados internacionales, se desarrolle, para que exista armonía e integralidad entre el ordenamiento interno e interamericano; y para que este tipo de casos políticos en nuestro ordenamiento jurídico sean historia, todo en aras de la defensa del derecho, de la seguridad jurídica y del respeto a los derechos humanos.

\section{REFERENCIAS}

Comisión Interamericana de Derechos Humanos. (2009). Demanda ante la Corte Interamericana de Derechos Humanos en el caso de Leopoldo López Mendoza contra la República Bolivariana de Venezuela. 14 de diciembre de 2009.
Comisión Interamericana de Derechos Humanos. (2014a). Resolución 5/2014. Gustavo Francisco Petro Urrego respecto de la República de Colombia. Medida cautelar No. 314-13. 18 de marzo de 2014.

Consejo de Estado de Colombia. Sala Plena de lo Contencioso Administrativo. (2014). Radicado No. 25000234200020130687101. (Consejero ponente: Guillermo Vargas Ayala, 18 de febrero de 2014).

Corte Constitucional de Colombia. Sala Plena de la Corte Constitucional. (2006). Sentencia C-028/2006. (Magistrado ponente: Humberto Antonio Sierra Porto, 26 de enero de 2006).

Corte Constitucional de Colombia. Sala Plena de la Corte Constitucional. (2013). Sentencia SU-712/2013. (Magistrado ponente: Jorge Iván Palacio Palacio, 17 de octubre de 2013).

Corte Interamericana de Derechos Humanos. (2011). Caso López Mendoza vs. Venezuela. Fondo Reparaciones y Costas. Sentencia de 1 de septiembre de 2011 Serie C No. 233.

Jiménez, J. (2013, 9 de diciembre). Los destituidos por Ordóñez. El Espectador. Recuperado de http://www.elespectador.com/noticias/nacional/ los-destituidos-ordonez-articulo-463201

Tribunal Administrativo de Cundinamarca. Sección Segunda Subsección A. (2014). Referencia A. T. No. 2013-07052-00. (Magistrado ponente: José María Armenta Fuentes, 13 de enero de 2014).

Tribunal Administrativo de Cundinamarca. Sección Segunda Subsección C. (2014). Referencia A. T. No. 2013-06871. (Magistrado ponente: Samuel José Ramírez Poveda, 17 de enero de 2014).

Tribunal Administrativo de Cundinamarca. Sección Tercera Subsección A. (2014). Radicación No. 25000233600020130223600. (Magistrada ponente: Bertha Lucy Ceballos Posada, 23 de enero de 2014). 